\title{
DIFUNDINDO PRÁTICAS E INSTRUMENTOS OPERACIONAIS PARA PROMOVER O DIREITO À MORADIA ADEQUADA
}

\author{
DISSEMINATING PRACTICAL AND OPERATIONAL TOOLS TO PROMOTE, \\ MONITOR AND IMPLEMENT THE HUMAN RIGHT TO ADEQUATE HOUSING
}

*Raquel Rolnik, **Márcia Saeko Hirata, ***Paula Ligia Martins, ****Joyce Reis Ferreira da Silva

\section{RESUMO}

É notável o enorme distanciamento entre a dimensão da moradia adequada como direito fundamental do ser humano (reconhecido por diferentes tratados e convenções internacionais) e a real e efetiva incorporação de tal conceito nas políticas públicas para o setor (por governos nacionais em todos os níveis da administração pública e nas práticas dos atores envolvidos em programas habitacionais e de planejamento urbano). Ao assumir o cargo de Relatora Especial para o Direito à Moradia Adequada da ONU, a Profa. Dra. Raquel Rolnik decidiu dedicar esforços neste sentido, para tornar pública e acessível aos diversos atores da sociedade as ferramentas e documentos já produzidos pela Relatoria Internacional. Para isto, inseriu o tema na agenda de pesquisa e extensão desenvolvida na Faculdade de Arquitetura e Urbanismo (FAU) da Universidade de São Paulo. O subtema escolhido para desenvolvimento das atividades foi o das remoções e despejos forçados resultantes de projetos de infraestrutura e urbanização. Como material resultante é apresentado um guia e folheto elaborados com linguagem clara e acessível, destinado aos técnicos do setor público e a organizações não governamentais, aos movimentos de luta pela moradia, aos estudantes e professores que trabalham com o tema.

Palavras-chave: Direito à moradia adequada. Projetos de desenvolvimento. Remoções forçadas.

\section{ABSTRACT}

It is striking the huge gap between the dimension of adequate housing as a fundamental human right recognized by various international treaties and conventions and the real and effective incorporation of such concept in public policy developed by governments at all levels of the public administration and in the practices developed by different actors involved in housing programs and urban planning. By assuming the post of UN Special Rapporteur on the Right to Adequate Housing, professor Raquel Rolnik decided to dedicate efforts in this direction, to make public and accessible to various actors of society the tools and documents already produced by the International Rapporteur. For this purpose, she placed the matter on the agenda of research and extension developed at the School of Architecture and Urbanism of this University. The sub-theme chosen for the development of activities were the removals and forced evictions resulting from projects of infrastructure and urbanization. The material produced is presented as a guide and a leaflet, with a clear and accessible language, for the technicians of the public sector, non-governmental organizations, movements struggling for housing, students and teachers who work with the theme.

Key words: Right to housing. Development projects. Forced eviction.

\footnotetext{
* Professora Doutora da Faculdade de Arquitetura e Urbanismo da Universidade de São Paulo (FAU-USP), Relatora especial do Conselho de Direitos Humanos da ONU para o Direito à Moradia Adequada, Coodenadora do Laboratório Espaço Público e Direito à Cidade - e-mail: raquelrolnik@gmail.com. ** Doutoranda da FAU-USP. *** Advogada pesquisadora do Laboratório Espaço Público e Direito à Cidade (FAU-USP). **** Arquiteta pesquisadora do Laboratório Espaço Público e Direito à Cidade da FAU-USP.
} 


\section{INTRODUÇÃO}

O Direito à moradia adequada tem sido amplamente discutido em vários fóruns e instâncias internacionais, sendo reconhecido como um dos direitos humanos básicos no âmbito dos direitos econômicos, sociais e culturais. No entanto, a existência do Direito à moradia adequada e de seus elementos ainda circula na restrita esfera dos especialistas da área de direitos humanos, tendo sido pouco incorporada à prática das políticas de habitação e desenvolvimento urbano. Desde o início dos trabalhos da Relatoria Especial sobre Moradia Adequada, em 2000, o mandato tem desenvolvido ferramentas práticas para auxiliar Estados, organizações internacionais e sociedade civil a implementar o Direito Humano à Moradia Adequa$\mathrm{da}^{\dagger}$. Essas ferramentas incluem, entre outros, um guia contendo um conjunto de "Orientações básicas para casos de ameaça de despejos em função de projetos de desenvolvimento" (Basic Principles and Guidelines on Development-based Evictions and Displacement) $)^{\ddagger}$. Tais ferramentas destinam-se ao auxílio dos Estados e da comunidade internacional no desenvolvimento de políticas, práticas de projeto e de legislação urbanística que evitem despejos forçados, integrando as alternativas de moradia para os atingidos como elemento essencial do próprio projeto.

Como se afirmou anteriormente, objetivou-se diminuir o enorme distanciamento entre o reconhecimento da moradia adequada como direito fundamental do ser humano por diferentes instâncias internacionais e a real e efetiva incorporação de tal conceito no desenvolvimento de políticas públicas para o setor por governos nacionais em todos os níveis da administração pública e nas práticas dos atores envolvidos em programas habitacionais e de planejamento urbano. Para isso, o projeto aqui relatado se dispôs a trabalhar com o tema "remoções forçadas", com base nos "Guidelines” já desenvolvidos pela relatoria, propondo a criação de alguns instrumentos práticos em linguagem acessível, ricos em exemplos práticos e amplamente

$\dagger \quad$ A resolução que criou o mandato de relator foi votada no Conselho dos Direitos Humanos da ONU em 2000. Miloon Khotari, de origem indiana, foi o primeiro relator e permaneceu no cargo por 7 anos. Em maio de 2008, o Conselho indicou a Profa. Dra. Raquel Rolnik para sucedê-lo nesta missão até maio de 20 II $[4,5]$.

$\ddagger \quad$ Este documento foi elaborado no mandato do primeiro relator [I3]. ilustrados que alcancem o público ainda não familiarizado com a linguagem do direito.

O presente artigo relata como foi o processo de elaboração dos materiais propostos, cujo objetivo exigiu o envolvimento de diversos atores que lidam na prática com o tema, culminando na redação do material de disseminação mencionado em linguagem não especializada e acessível a todos.

\section{A RELATORIA ESPECIAL PARA O DIREITO À MORADIA ADEQUADA DA ONU E O TEMA "REMOÇÕES FORÇADAS"}

A Relatoria Especial para o Direito à Moradia Adequada da ONU foi criada em 2000. Sua função é examinar, monitorar, aconselhar e relatar a situação do direito à moradia no mundo, promover assistência a governos e a cooperação para garantir melhores condições de moradia, assim como estimular o diálogo com os outros órgãos da ONU e organizações internacionais com o mesmo fim. O Relator é um especialista nomeado pelo Conselho de Direitos Humanos da ONU. Ele exerce seu trabalho de forma independente, não integra os quadros da ONU e tem mandato de três anos, com possibilidade de uma recondução.

Entre outras funções, o Relator Especial para o Direito à Moradia Adequada pode realizar pesquisas e apresentar relatórios que versem sobre temas específicos relativos à sua área de atuação. Até hoje, os relatores já apresentaram documentos sobre vários aspectos do direito à moradia, tais como: acesso à água; crise financeira; discriminação; mulheres; justiciabilidade; mudanças climáticas; despejos forçados. Este último tem se mostrado um dos mais recorrentes temas de trabalho da Relatoria. Isso porque o Relator recebe anualmente inúmeras denúncias de despejos forçados realizados todos os anos em vários países ao redor do mundo.

Os despejos e remoções forçadas não são uma exclusividade dos países em desenvolvimento. Eles ocorrem por toda parte e podem ter diferentes e variadas causas. $\mathrm{O}$ impacto das operações desta espécie é imenso. Há décadas instituições nacionais e internacionais têm reconhecido os traumas de longo prazo que podem assolar as populações atingidas. Os efeitos negativos são de cunho material e também psicológico e, não raro, culturais. Infelizmente, é muito comum que os despejos e remoções forçados venham acompanhados de brutalidade e violência [15]. 
Em razão da extensão do problema em todo o mundo, a ONU tem dedicado especial atenção ao tema e normas foram elaboradas para orientar os Estados sobre como atuar em tais situações [5]. No intuito de colaborar com tais iniciativas e para complementar os estudos que já havia realizado sobre o assunto, o Relator Especial anterior à professora Rolnik, o urbanista indiano Miloon Kothari, elaborou recomendações detalhadas na forma do documento Princípios Básicos e Orientações para Remoções e Despejos Causados por Projetos de Desenvolvimento [13] $]^{\S}$,já mencionado anteriormente.

Os Princípios Básicos sistematizam as normas internacionais sobre a matéria através de recomendações aos Estados sobre como realizar despejos e remoções legítimos segundo os padrões internacionais de direitos humanos. Embora de enorme riqueza, os Princípios Básicos foram redigidos utilizando uma linguagem técnica do direito internacional.

\section{DIFUNDINDO PRÁTICAS E INSTRUMENTOS OPERACIONAIS PARA PROMOVER O DIREITO À MORADIA ADEQUADA}

O caminho escolhido para realização do projeto foi o de desenvolver instrumentos de comunicação destinados a difundir nos países o Direito à Moradia Adequada como componente essencial de projetos de intervenção no território que impliquem em deslocamento ou remoção de habitantes. Para isso tornamse os instrumentos operacionais já desenvolvidos no âmbito do Conselho dos Direitos Humanos [13-15] a este respeito, acessíveis a um público não especializado em direitos humanos, especialmente para os atores envolvidos em políticas de habitação e planejamento urbano, tais como técnicos, estudantes e professores de arquitetura, urbanismo e engenharia, ONGs, movimentos populares e profissionais de mídia.

Foram idealizados dois produtos principais para esse fim: um guia detalhado (que reformula o texto dos Guidelines [1-13], porém mantendo a íntegra de seu conteúdo) e um folheto resumindo seus pontos principais (dez itens bastante sintéticos sobre o que fazer e o que não fazer). O guia seria redigido com

§ Texto integral disponível em www.ohchr.org. a finalidade de fornecer subsídios aos atores envolvidos no desenvolvimento de projetos de infraestrutura e urbanização que possam gerar despejos e remoções forçadas. Já o folheto foi pensado para distribuição entre populações afetadas ou ameaçadas por projetos deste tipo. Todo um processo preparatório foi idealizado para direcionar e alimentar a redação deste material. Atenção especial foi dada à coleta de testemunhos e experiências que pudessem guiar a equipe na redação do texto, de forma a garantir a utilidade das orientações e sua aplicação prática.

\section{METODOLOGIA}

Inicialmente foram realizados estudos preparatórios para compreender o sistema internacional de proteção dos direitos humanos e a situação específica de alguns grupos que sofrem de maneira mais acentuada o problema das remoções e despejos forçados [3], como as populações indígenas, os trabalhadores rurais sem terra, os atingidos por barragens [16] etc. Com base nestes estudos preparatórios, a equipe fez um material inicial que foi apresentado para avaliação e comentários durante oficinas abertas.

A etapa seguinte contou com a realização de quatro oficinas com a presença de público externo, entre acadêmicos, representantes do poder público, de ONGs e de comunidades atingidas. As oficinas foram divididas nos seguintes temas:

- Projetos que envolvem remoção no meio urbano do ponto de vista dos movimentos sociais e ONGs [10];

- Projetos que envolvem remoção no meio rural (com destaque para o impacto de projetos de desenvolvimento das populações indígenas e ribeirinhas e dos pequenos produtores rurais) $[9,16]$;

- Projetos que envolvem remoção no meio urbano, direcionada ao público técnico (gestores públicos, assessorias técnicas) $[2,6,7]$;

- Projetos que envolvem remoção no meio rural e urbano, reunindo seus diversos atores (técnicos envolvidos com a elaboração de projetos; representantes de secretarias de habitação; representantes de ONGs; centros de assistência universitária; representantes de movimentos sociais, estudantes universitários, entre outros). 
O fechamento dessa etapa de consultas ocorreu através da realização de um seminário aberto ao público, que teve objetivo principal introduzir o tema "Projetos que envolvem remoções" ao público da graduação e demais interessados, incentivando a troca de experiências e ideias entre movimentos sociais e estudantes, através do depoimento dos convidados presentes à mesa e da participação da plateia.

Concomitante a estes debates, foi-se constantemente consolidando o conteúdo desenvolvido, ou seja, conforme o guia e o folheto iam sendo redigidos e modificados, novas reuniões e oficinas eram realizadas para análise das alterações introduzidas, visando se constituir uma estratégia de construção coletiva e colaborativa, retroalimentada por avaliações constantes.

\section{RELATO SOBRE O PROCESSO DE ELABORAÇÃO DO MATERIAL}

Os estudos preparatórios contaram com discussões internas realizadas com a participação de especialistas temáticos convidados, tais como o jurista Nelson Saule, a indigenista Ana Valéria Araújo, a especialista em direitos humanos Graciela Dede e o advogado e urbanista Edésio Fernandes. Também foram analisados os tratados internacionais sobre o tema e as normas brasileiras mais relevantes. Outros encontros foram dedicados a identificar exemplos nos quais podiam ser identificados alguns elementos de inovação e impacto positivo na atuação do poder público em ações de despejo e remoção.

As quatro oficinas realizadas com o público externo apresentaram o resultado dos estudos preliminares desenvolvidos pela equipe e debateram um tema específico.

$\mathrm{Na}$ primeira oficina, os participantes ligados à mobilização social (movimentos sociais e organizações não governamentais) ressaltaram a importância de efetivamente considerar-se a moradia como um direito humano, independente da propriedade ou de titulação; o direito de viver em condições dignas e seguras deve ser um direito de todos e em qualquer circunstância e isso deveria ser explicitado pelo material em preparação. Ao mesmo tempo, admitiu-se que existem casos em que as remoções são necessárias, quando não urgentes. A questão principal é garantir que as pessoas sejam tratadas com respeito durante todo o processo. Informação e participação são essenciais. Os presen- tes à oficina também lembraram que é preciso reiterar que, ao final dos processos de remoção, as pessoas afetadas devem receber algum tipo de solução definitiva para sua situação de moradia, seja na forma de uma indenização monetária, de volta ao local de moradia original após a conclusão do projeto de urbanização ou similar, ou o reassentamento em local que atenda a padrões apropriados de habitabilidade. Também foi sugerido que o material, especialmente o folheto, chamasse as pessoas a unirem esforços e articularemse para defesa de seus direitos, assim como fornecesse recomendações práticas para esse fim.

A segunda oficina foi muito mais focada na situação das áreas rurais, com destaque para o impacto de projetos de desenvolvimento das populações indígenas e ribeirinhas e de agricultores familiares. Os imensos custos sociais e ambientais da construção de barragens/hidrelétricas e estradas de rodagem receberam destaque. A relação especial que estes grupos possuem com a terra foi repetidamente lembrada. Para eles, a terra não é apenas o local de moradia, mas a fonte de onde tiram sua subsistência e, muitas vezes, a base de suas práticas culturais.

A terceira oficina foi mais direcionada ao público técnico, urbanistas e gestores públicos. Este encontro propiciou uma discussão invertida da questão, não a partir do ponto de vista dos atingidos por projetos de infraestrutura e urbanização, mas daqueles que tentam desenvolver tais projetos de forma adequada e de visão pública, apontando os limites e obstáculos reais para a implementação dos princípios.

A quarta e última oficina teve por base os textos revisados do folheto e do guia, já incorporados os comentários e sugestões das oficinas anteriores, e contou com a presença de técnicos envolvidos com a elaboração de projetos; representantes de secretarias de habitação da vários municípios da Grande São Paulo; representantes de ONGs; centros de assistência universitária; representantes de movimentos sociais; movimentos de moradia; entre outros.

O seminário público contou com a presença de aproximadamente 130 pessoas, entre estudantes e professores de arquitetura e urbanismo, geografia, direito e jornalismo; técnicos do governo, empresas públicas e setor público municipal de habitação; membros de organizações não governamentais; movimentos de luta pela moradia; movimentos sociais do meio rural, inclusive de outros estados da federação. Foi transmitido 
ao vivo pela Internet, através do sistema IPTV-USP, o que permitiu a visualização do conteúdo em tempo real por pessoas que não puderam se deslocar até o referido seminário (de acordo com dados do sistema, aproximadamente 200 pessoas se conectaram ao vídeo do seminário durante sua realização). O seminário teve como objetivo principal introduzir o tema "Projetos que envolvem remoções”, ao público da graduação, incentivando a troca de experiências e ideias entre movimentos sociais e estudantes, através do depoimento dos convidados presentes à mesa e da participação da platéia.

Resumidamente, sobre o meio rural, a fala do indígena Luiz Xipaia deu um panorama sobre a implantação da Hidrelétrica Belo Monte, que afetará entre outros locais, o município de Altamira, onde se encontra a tribo indígena Xipaia; em seguida, Ewerton Libório apresentou um vídeo sobre os atingidos por barragens e mostrou um painel sobre a hidrelétrica de Tijuco Alto e seu impacto sobre comunidades tradicionais quilombolas; Hélio Mecca traçou um cenário da implantação de hidrelétricas no Brasil e seu impacto social. Sobre o meio urbano, Marcelo Edmundo falou sobre grandes projetos realizados no Rio de Janeiro, destacando as obras dos Jogos Pan-americanos e trazendo informações sobre projeto Porto Maravilha; e na sequência, Evaniza Rodrigues falou sobre processos de reurbanização de favelas na cidade de São Paulo diante das políticas habitacionais municipais atuais. A professora Raquel Rolnik encerrou o seminário fazendo a relação entre os depoimentos ouvidos e os possíveis meios de atuação do poder público e da Relatoria do Direito à Moradia, pontuando quais são os principais desafios existentes entre a execução de grandes projetos e o respeito ao direito à moradia. Por fim, foi aberto o debate público, onde questões foram levantadas por estudantes (de jornalismo, urbanismo e direito); técnicos de empresas públicas (Companhia Paulista de Transporte Metropolitano), técnicos de prefeituras (Secretarias de Habitação das cidades de São Paulo e Suzano) e do governo federal (Ministério das Gidades); assessores de deputados (Deputado Estadual Simão Pedro); representantes de ONGs (Cohre, Centre on Housing Rights and Evictions) e membros de movimentos sociais (do Rio de Janeiro, de São Paulo).

O debate propiciou aos presentes uma discussão pública e aberta sobre um tema atual e de extrema relevância para a formação e capacitação profissional de arquitetos, urbanistas, advogados e gestores públicos. Além disso, a presença de representantes de movimentos sociais e de comunidades tradicionais (como indígenas e quilombolas) propiciou uma reflexão e aproximação da realidade e demanda existentes em relação às políticas públicas de desenvolvimento urbano e habitacional.

\section{O MATERIAL PRODUZIDO}

GUIA

Como explicitado, todo um processo preparatório foi idealizado para direcionar e alimentar a redação deste material. Atenção especial foi dada à coleta de testemunhos e experiências que pudessem guiar a equipe na redação do texto, de forma a garantir a utilidade das orientações e sua aplicação prática. A linguagem gráfica seguiu essa diretriz e objetivou uma interação dinâmica e universal com o leitor e suas necessidades para incorporação do conteúdo do Direito à Moradia Adequada.

O guia (ver Anexo) foi organizado dentro da seguinte estrutura:

- O que é o direito à moradia?

- A relatoria da ONU para o direito à moradia adequada;

- A ONU e as remoções forçadas;

- Como atuar em projetos que envolvem despejos e remoções:

$\gg$ Antes

$\gg$ Durante

》Depois

- Política permanente de prevenção a remoções;

- Algumas recomendações específicas;

- Como fazer uma denúncia;

- Anexos.

O conteúdo central do guia está concentrado no capítulo "Como atuar em projetos que envolvem despejos e remoções". Esse capítulo foi dividido nas seções Antes / Durante / Depois, com o objetivo de sistematizar as sugestões práticas em uma estrutura sequencial lógica e cronológica, embora intersecções sempre ocorram. É aí que estão concentradas as recomendações efetivas, a começar pela necessidade de uma política de prevenção que vise evitar a ocorrência de operações de despejo e remoção. Caso realmente seja 
inevitável, a remoção deve garantir um processo participativo com o envolvimento real da população atingida. A seção "Durante" informa sobre ações absolutamente proibidas pela normativa internacional, como o uso da violência e da intimidação, ou operações que resultem em famílias desabrigadas, bem como indica o passo a passo para o momento de retirada e transferência dos indivíduos afetados e seus pertences. Finalmente, a seção "Depois" traz cuidados a serem tomados na definição de moradia provisória, se necessária, e da solução definitiva ao final do processo, que pode envolver a restituição e retorno, o reassentamento ou a justa indenização. Caixas de texto foram introduzidos ao longo de todo o guia com exemplos reais de casos [8, $11,12]$ onde medidas interessantes foram tomadas que exemplificam algumas das recomendações constantes da publicação - ao todo foram inseridos oito estudos de caso. Também foram incorporadas áreas com questões direcionadas ao usuário do guia a fim de proporcionar um momento de interatividade que pode ser utilizado para inserção de especificidades locais ou em programas de sensibilização e treinamento que façam uso do guia como material de apoio e/ou referência.

\section{FOLHETO}

O folheto (ver Anexo) sumariza, em dez recomendações essenciais, o conteúdo do guia. Além disso, em breve introdução, ele aponta os elementos do que pode ser considerado como moradia adequada, ressaltando que o conceito vai muito além da ideia de mero abrigo, de um teto e quatro paredes, incluindo também um meio ambiente saudável, condições de habitabilidade e acesso a serviços públicos e a fontes de renda e emprego, entre outros. Como mencionado anteriormente, o folheto foi pensado como material de referência para as populações atingidas por projetos de urbanização e infraestrutura ou por eles ameaçadas; além disso, o seu conteúdo foi definido após apresentação do material completo a representantes de vários grupos atingidos, movimentos sociais e ONGs para eleição das recomendações que seriam mais essenciais e úteis ao público-alvo. Ao final, o folheto dá ênfase à importância da mobilização e articulação entre as famílias afetadas pelas operações de remoção, para que sua organização possa facilitar as negociações com o poder público e fortalecer suas demandas. O folheto também indica alguns locais onde assistência jurídica ou de outra espécie pode ser encontrada.
A linguagem gráfica buscou a distribuição clara e direcionada das diferentes informações necessárias ao público alvo, para utilização prática principalmente em debates coletivos.

De forma abreviada, seguem os dez pontos principais do folheto:

I. A comunidade que será atingida deve ter tempo e condições hábeis para participar de todo o processo;

2. Todos têm o direito de receber informações completas sobre sua remoção e sobre o projeto, essas informações devem ser disponibilizadas com antecedência e redigidas de maneira clara no idioma dos afetados;

3. A remoção não pode resultar em pessoas ou comunidades desabrigadas;

4. Depois de realizada a obra, a melhor alternativa é o retorno ou restituição. Se isto for impossível, deve haver acordo sobre o local e o modo como se dará o reassentamento;

5. O reassentamento deve anteceder a remoção, fornecer condições de habitação iguais ou melhores que as originais, não pode gerar segregação e deve vir acompanhado de políticas de reinserção social;

6. O Estado deve garantir assistência social e jurídica, assegurando-se a possibilidade de defesa e recurso ao judiciário;

7. A remoção não pode ocorrer em datas e condições climáticas inadequadas e as pessoas devem receber apoio das autoridades para o transporte e guarda de suas famílias e bens;

8. Boas condições de acesso à saúde, educação, trabalho e outros não podem ser comprometidos pelas remoções. Mulheres e grupos em situação vulnerável têm proteção especial da lei e devem sempre receber cuidados específicos;

9. Os removidos têm direito à justa compensação pelos danos sofridos, que devem ser avaliados de forma ampla;

IO. Qualquer forma de violência ou intimidação antes, durante ou depois da remoção é proibida.

\section{RESULTADOS ALCANÇADOS}

Como resultados quantitativos têm-se a impressão inicial de 2.000 guias "Como atuar em projetos que envolvem despejos e remoções?" e 2.400 folhetos 
“Querem nos despejar. E agora?", distribuídos e disponibilizamos no site da Relatoria (inclusive para download e impressão), circulando eletronicamente para autoridades públicas e outros atores interessados. A agência internacional sueca Swedish International Development Cooperation Agency (SIDA), interessada no resultado deste projeto, financiou a impressão de mais 8.000 folhetos e de mais 6.000 guias para distribuição no $\mathrm{V}$ Fórum Urbano Mundial realizado na cidade do Rio de Janeiro em março de 2010 (para tanto, o material foi traduzido em inglês, espanhol, francês e árabe).

Em termos qualitativos, sobre os resultados dos encontros, oficinas e seminário para discussão do conteúdo do guia e do folheto ressalta-se que se estabeleceu um rico debate sobre as ferramentas e conceitos fundamentais a serem ressaltados na prática da busca pela concretização do direito à moradia, em consonância com as necessidades da sociedade. O guia e o folheto elaborados, por sua vez, são ferramentas para garantir o direito à moradia no caso de implantação de projetos de desenvolvimento, destinados especialmente para os atores envolvidos em políticas de habitação e planejamento urbano.

Isso foi feito por meio da participação de estudantes de graduação e pós-graduação em todo o projeto, desde os estudos preparatórios, realização de reuniões, entrevistas, oficinas e seminário, e redação do guia e folheto, assim como pela organização de uma oficina e um seminário aberto realizados nas dependências e com o apoio da FAU-USP. A presença de público considerável em ambas as atividades é um indicativo do interesse gerado entre os alunos e professores da unidade.

Em termos disciplinares relacionados ao planejamento urbano e política habitacional, o seminário público visou aprimorar o conhecimento aplicado e técnico acerca do direito à moradia, fomentando a abrangência pluridisciplinar do tema, e abrindo novas possibilidades metodológicas para elaboração de estudos e atividades específicas ligadas ao direito à moradia. O material final elaborado pelo projeto foi enviado a diversas secretarias de habitação, planejamento, ministérios afins e órgãos relacionados ao provimento da justiça (como Defensorias, Ministérios Públicos e associações de magistrados), bem como para outros laboratórios e bibliotecas universitárias privadas e públicas de São Paulo e outros estados. Como consequência desses encontros tem-se o fortalecimento da interlocução entre os participantes em um ambiente interativo sobre diferentes experiências de diversos setores sociais, consolidando os avanços na realidade do direito à moradia adequada.

\section{CONCLUSÃO}

A interação entre Relatoria e Universidade propiciou a introdução de conteúdo ainda pouco incorporado ao ensino e pesquisa do planejamento urbano e política habitacional tanto no país, quanto na própria FAU-USP (onde serão formados os futuros formuladores e implementadores das políticas públicas de planejamento e habitação) e demonstrou uma importância e premência que merece ser amplamente abordado e utilizado em sala de aula, bem como reforçar as pesquisas sobre o tema.

Além disto, os resultados alcançados neste projeto igualmente potencializarão outros projetos em desenvolvimento, relacionados ao trabalho da Relatoria Especial do Direito à Moradia Adequada das $\mathrm{Na}$ ções Unidas na FAU-USP. As conversas e debates realizados foram momentos de diálogo e esclarecimento sobre o papel e a forma como vem atuando a relatoria, bem como oportunidades de aprimoramento da estratégia de comunicação em construção pela relatora (cuja principal plataforma é um website temático) e de suas interações com a sociedade civil organizada.

\section{REFERÊNCIAS BIBLIOGRÁFICAS}

[1] AMnistia INTERNAGIONAL (Angola). Princípios básicos e directrizes sobre as expulsões e o deslocamento com origem no desenvolvimento (tradução para o português). Angola, 2007.

[2] BRASIL. Banco de experiências de regularização fundiária no Brasil, Secretaria de Programas Urbanos do Ministério das Cidades. Disponível em: www. cidades.gov.br/secretarias-nacionais/programas-urbanos/biblioteca/regularizacao-fundiaria/experiencias-de-regularizacao-fundiaria-no-brasil/se/Coroa. pdf

[3] COHRE. Forced Evictions and Human Rights, a manual for action. COHRE International Secretariat, Genebra, I999. 
[4] COMMITTEE ON ECONOMIC, SOCIALAND CULTURAL RIGHTS. General Comment n. 4 - The right to adequate housing, Nações Unidas, Genebra, I99I.

[5] COMMITTEE ON ECONOMIG, SOGIAL AND GULTURAL RIGHTS. General Comment n. 7 The right to adequate housing: forced evictions, Nações Unidas, Genebra, I997.

[6] Denaldi, R.; Oliveira, M. G. de. Community Participation in Relocation Programs: The case of the Slum Sacadura Cabral in Santo André - Brazil. I999. Open House International, v. 24, n. 3 .

[7] DENALDI, R. Planos Locais de Habitação de Interesse Social: Estratégia de Ação do Ministério das Gidades, Brasil. Livro organizado para curso à distância: Planos Locais de Habitação de Interesse Social. Brasília: Ministério das Cidades, 2009.

[8] DING, G. Working Paper: Land Acquisition in China: Reform and Assessment. Lincoln Institute of Land Policy, 2005.

[9] ELETROSUL e GRAB. Diretrizes e critérios para planos e projetos de reassentamentos rurais de populações atingidas pelas Usinas Hidrelétricas de Itá e Machadinho. Grupo de Trabalho estabelecido entre ELETROSUL e CRAB, I987.

[10] ESCRITÓRIO USINA E MOVIMENTO DOS TRABALHADORES SEM TERRA. Relatório: "Construção da moradia rural por autogestão, Assentamento Comuna da Terra Dom Tomás Balduíno”, Franco da Rocha, São Paulo, 2008.

[11] HABITAT INTERNATIONAL COALITION. Longos: Community Struggle against Forced Displacements, 2004. Disponível em: http://www.hicnet. org/document.php?pid $=2430$

[12] HABITAT INTERNATIONAL GOALITION. Loss Matrix. http://www.hic-mena.org/documents/ Loss\%20Matrix.pdf

[13] KOTHARI, M. Basic Principles and Guidelines on Development-Based Evictions and Displacement. Relatoria especial do Direito à Moradia Adequada do Conselho de Direitos Humanos da ONU, 2007.

[14] UNITED NATIONS GENTRE FOR HUMAN RIGHTS. Human Rights Fact Sheet n. 2I on the Right to Adequate Housing, Nações Unidas, Genebra, I993.

[15] UNITED NATIONS GENTRE FOR HUMAN RIGHTS. Human Rights Fact Sheet n. 25 on Forced Evictions and Human Rights, Nações Unidas, Genebra, I996.

[16] VAINER, G. B. O conceito de atingido: Uma revisão do debate e Diretrizes. Julho/2003, Mimeo. 


\section{ANEXO}

\section{IMAGENS DO GUIA}

COMO

ATUAR EM

PROJETOS

QUE

ENVOLVEM

DESPEJOSE

REMOÇOEES?

\section{ALGUMAS}

RECOMENDAÇÕES ESPECÍFICAS...

$\rightarrow$ Agentes financiadores - Banco Mundial, BID, agências usar esses padross comio criterio para repasse de recursos e como

$\rightarrow$ Judiciário: envolver-se efetivamente no caso e buscar conhecer a situação visitando o local de remoçăo, assim como assegurar que os mais variados atores sejam ouvidos durante o processo

$\rightarrow$ Técnicos: valorizar a opiniāo da população e não desqualificá-la por nẫo se tratar de saber técnico; conhecer a populaçāo $\mathrm{e}$ a área afetada antes de desenvolver o projeto; os técnicos também devem procurar saber se existem acordos com a comunidade ale
observados quando do planejamento do projeto

$\rightarrow$ Força Policial: buscar um diálogo prévio com a população afetada antes da data da operação do despejo; os policiais também devem se abster, e garantir que seus colegas se abstenham, do uso da intimidaçăo e da violência.

$\rightarrow$ ONGs e entidades defensoras de direito: auxiliar na mobilizaçāo da comunidade atingida, ajudar na orientação sobre direitos, facilitar a comunicação e a informação à comunidade.

$\rightarrow$ Comunidades atingidas: mobilizar e buscar alternativas para dar visibilidade à sua luta; buscar a midia e organizaçōes parceiras, recorrer a estratégias variadas, inclusive a açâo pollitica e o uso do judiciário.

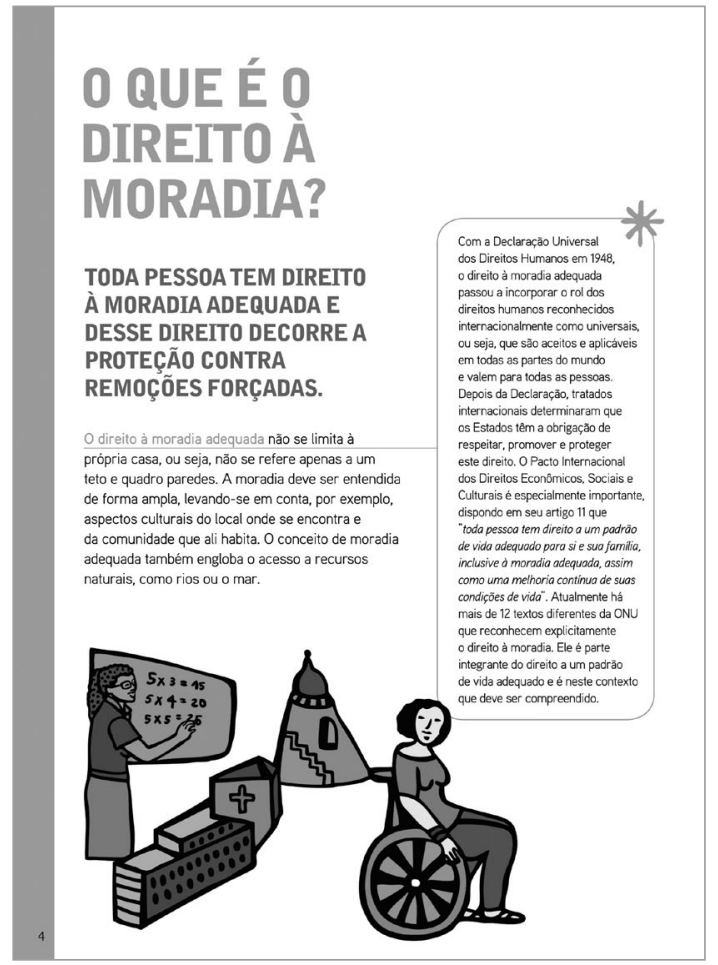

\section{ANEXO}

NORMAS E PADRÕES INTERNACIONAIS

\begin{tabular}{|c|c|}
\hline TEMAS & NORMAS \\
\hline $\begin{array}{l}\text { Tratados internacionais de } \\
\text { direitos humanos do sistema ONU } \\
\text { que protegemo odreito a } \\
\text { moradia adequada }\end{array}$ & 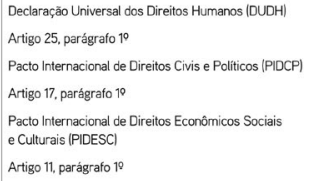 \\
\hline $\begin{array}{l}\text { Tratados regionais de direitos } \\
\text { humaros que protegem o } \\
\text { direito à moradia adequada }\end{array}$ & 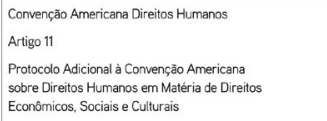 \\
\hline Sotre o conteúdo do direto à moradia & $\begin{array}{l}\text { Comentário Geral No. } 4 \text { do Comitê de Direitos Econônicos, } \\
\text { Sociais e Culturais }\end{array}$ \\
\hline Sobre despejos forç,ados e remoç̄öes & $\begin{array}{l}\text { Comentário Geral No. } 7 \text { do Comitê de Direitos } \\
\text { Econômicos, Sociais e Culturais } \\
\text { United Nations Comprehensive Guidelines on } \\
\text { Development-Eased Displecement, } 1997 \\
\text { Basic Principles and Guidelines on Development-Based } \\
\text { Evictions and Displacement, } 2007\end{array}$ \\
\hline Discriminaçāo & $\begin{array}{l}\text { Convenção Internacional sobre a Eliminação de Todas } \\
\text { as Formas de Discriminaçăo Racial } \\
\text { Arrigo 5, e, III } \\
\text { Convençăo Sobre a Eliminaç̧o de Todas as Formas de } \\
\text { Discriminaçăo Contra a Mulher } \\
\text { Artigo 14, parácrato } 20\end{array}$ \\
\hline
\end{tabular}



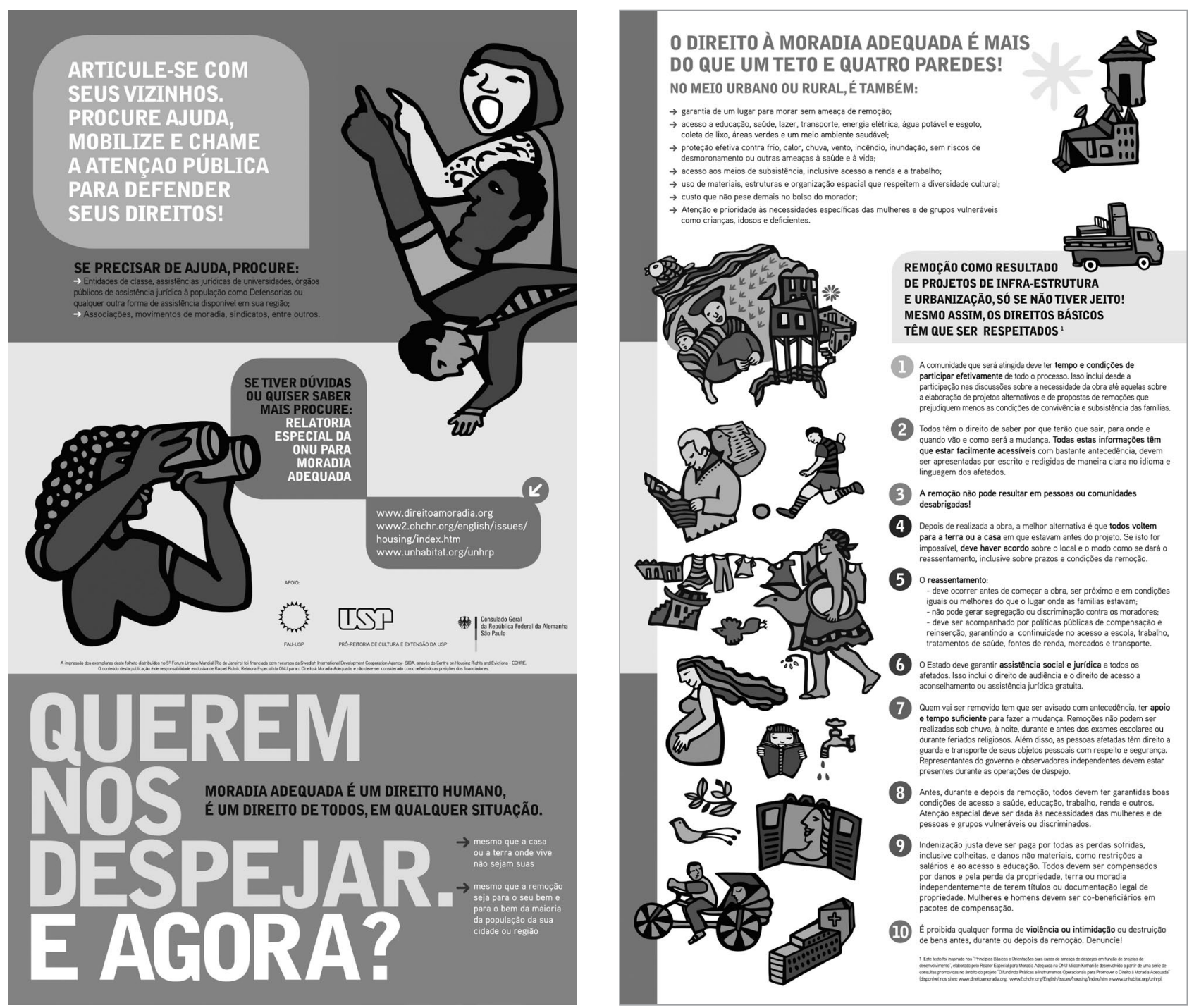